\title{
Sorption thermodynamic and kinetic studies of Lead removal from aqueous solutions by nano Tricalcium phosphate
}

\author{
Manuscrit reçu le 3 septembre 2016 et accepté le 5 mai 2017 \\ Davod GHAHREMANI ${ }^{1}$, Iman MOBASHERPOUR ${ }^{2}$, \\ and Seyed Abolkhasem MIRHOSSEINI ${ }^{1}$ \\ ${ }^{1}$ Department of Engineering, Maybod Branch, Islamic Azad University, Maybod, Iran. \\ ${ }^{2}$ Ceramics Department, Materials and Energy Research Center, P.O. Box 31787-316, \\ Karaj, Iran.
}

\begin{abstract}
Nano tricalcium phosphate particles were prepared by a wet method from aqueous solutions and characterized using TEM, XRD, and BET- $\mathrm{N}_{2}$ adsorption measurements. The potential of the synthesized nano tricalcium phosphate particles to remove $\mathrm{Pb}^{2+}$ cations from aqueous solutions was investigated in batch reactor under different experimental condition. The effects of initial concentration, adsorbent dosage, contact time and temperature were studied in batch experiments. The sorption of $\mathrm{Pb}^{2+}$ by nanoTCP increased as the initial concentration of lead ion increased in the medium. Various thermodynamic parameters, such as $\Delta G^{\circ}, \Delta H^{\circ}$ and $\Delta S^{\circ}$ were calculated. Thermodynamics of $\mathrm{Pb}^{2+}$ cation sorption onto nano-TCP system pointed at spontaneous and endothermic nature of the process. The pseudo-first order, pseudo-second order and intraparticle diffusion kinetic models were applied to study the kinetics of the sorption processes. The pseudo-second order kinetic model provided the best correlation $\left(\mathrm{R}^{2}>0.999\right)$ of the used experimental data compared to the pseudo-first order and intraparticle diffusion kinetic models. The maximum $\mathrm{Pb}^{2+}$ adsorbed was found to be $4761.90 \mathrm{mg} / \mathrm{g}$. It was found that the sorption of $\mathrm{Pb}^{2+}$ on nano-TCP was correlated well $\left(\mathrm{R}^{2}=0.982\right)$ with the Langmuir equation as compared to Freundlich and DubininKaganer-Radushkevich (D-K-R) isotherm equation under the concentration range studied. This study indicated that nano-TCP could be used as an efficient adsorbent for removal of $\mathrm{Pb}^{2+}$ from aqueous solution.
\end{abstract}

Keywords: Sorption, Thermodynamic, Kinetic, $\mathrm{Pb}^{2+}$, Nano Tricalcium phosphate.

\section{Introduction}

The adsorption procedures are introduced as a favorable way for the remediation of aquatic waste because of its efficacy, practicality and economical feasibility, as depending on the used adsorbents [1].

Lead is one of the most ubiquitous contaminants in the soil and aqueous environments. A severe environmental $\mathrm{Pb}$ contamination can often be found at shooting ranges where the soil $\mathrm{Pb}$ concentration sometimes exceeds $10000 \mathrm{mg} \mathrm{kg}^{-1}$ because of spent lead bullets. In Iran, many shooting ranges are generally located in mountainous regions and

Corresponding author e-mail: i.mobasherpour@merc.ac.ir ; iman.mobasherpour@gmail.com 
suffer from the degradation of natural vegetation due to $\mathrm{Pb}$ toxicity, which may have the potential to augment the $\mathrm{Pb}$ contamination via soil erosion. Therefore, development of cost-effective technologies is necessary to reduce the mobility and bioavailability of $\mathrm{Pb}$ in soil and water environments [2,3].

The low cost adsorbents are the naturally occurring materials with high abundance such as aluminosilicates, clay and zeolite [4]. Calcium phosphate minerals have also been considered amongst ideal low cost adsorbents because of their high sorption capacity for metal ions, the least solubility and the highest stability in a wide range of $\mathrm{pH}$, and high stability under reducing/oxidizing conditions [5].

Tricalcium phosphate (TCP) is a principal component of calcium phosphate compound and has been of interest in industry and medical fields. Its synthetic particles find many applications in bioceramic, catalysts, and powders for artificial teeth and bones paste germicides. These properties relate to various surface characteristics of TCP, e.g., surface functional groups, acidity and basicity, surface charge, hydrophilicity and porosity [6].

Nano-materials represent a promising application in a variety of areas due to their high surface area and reactivity and their ability to become dispersed in aqueous solution. Nano-material usually displays higher reactivity and sorption ability than the same material of normal size [7-10].

The objective of this preliminary study was to investigate the feasibility of $\mathrm{Pb}^{2+}$ removal from aqueous solution by nano TCP prepared by precipitation method. The dynamic behavior of adsorption was investigated on the effect of initial metal ion concentration, contact time, adsorbent mass and temperature of solution. The thermodynamic and kinetics parameters were also evaluated from the adsorption measurements. The Langmuir, Freundlich and D-K-R models were used to fit the equilibrium isotherm.

\section{Material and methods}

\subsection{Preparation of nano Tricalcium phosphate sorbents}

All chemicals used in this work were of analytical grade and the aqueous solutions were prepared using double distilled water. Nano Tricalcium phosphate compounds were prepared via solution-precipitation method [6] using $\mathrm{Ca}\left(\mathrm{NO}_{3}\right)_{2} .4 \mathrm{H}_{2} \mathrm{O}$ (AnalarNo.10305) and $\left(\mathrm{NH}_{4}\right)_{2} \mathrm{HPO}_{4}($ Merck No. 1205) as starting materials and ammonia solution as agents for $\mathrm{pH}$ adjustment.

A $250 \mathrm{ml}$ of $0.06 \mathrm{M}\left(\mathrm{NH}_{4}\right)_{2} \mathrm{HPO}_{4}$ solution was slowly added drop wise to the $250 \mathrm{ml}$ of $0.09 \mathrm{M} \mathrm{Ca}\left(\mathrm{NO}_{3}\right)_{2} .4 \mathrm{H}_{2} \mathrm{O}$ solution while being vigorously stirred at about $25{ }^{\circ} \mathrm{C}$. In all experiments the $\mathrm{pH}$ of $\mathrm{Ca}\left(\mathrm{NO}_{3}\right)_{2} \cdot 4 \mathrm{H}_{2} \mathrm{O}$ stock solutions was adjusted by ammonia at $\mathrm{pH}=11$. Under this condition, a stoichiometry composition can be easily achieved through the following reaction [6]:

$$
3 \mathrm{Ca}\left(\mathrm{NO}_{3}\right)_{2} \cdot 4 \mathrm{H}_{2} \mathrm{O}+2\left(\mathrm{NH}_{4}\right)_{2} \mathrm{HPO}_{4}+2 \mathrm{NH}_{4} \mathrm{OH} \rightarrow \mathrm{Ca}_{3}\left(\mathrm{PO}_{4}\right)_{2}+6 \mathrm{NH}_{4} \mathrm{NO}_{3}+4 \mathrm{H}_{2} \mathrm{O}
$$

Once the precipitation reaction was complete, the suspensions were centrifuged at 3000 $\mathrm{rpm}$ for 60 seconds to remove the precipitates. The resulting powders were next dried in an oven at $80{ }^{\circ} \mathrm{C}$ for 1 hour. The particles synthesized were characterized by the following methods. Transmission electron microscopy (TEM) was used to characterize TCP particles. For this purpose, particles were deposited onto $\mathrm{Cu}$ grids, which support a 
"holey" carbon film. The particles were deposited onto the support grids from a dilute suspension in acetone or ethanol. The particle shapes and sizes were characterized by diffraction (amplitude) contrast and, for crystalline materials, by high resolution (phase contrast) imaging. The specific surface area was determined from $\mathrm{N}_{2}$ adsorption isotherm by the BET method using a Micromeritics surface area analyzer model ASAP 2010. The crystal phase was identified by powder X-ray diffraction (XRD) using Siemens $(30 \mathrm{kV}$ and $25 \mathrm{~mA}) \mathrm{X}$-ray diffractometer with $\mathrm{Cu} \mathrm{K \alpha}$ radiation $(\lambda=1.5404 \AA)$ and XPERT software. Fourier-Transform Infra-Red (FTIR) analysis was conducted using Bruker Vector 33 FT-IR spectrometer. $\mathrm{KBr}$ was used for preparing of pellet shaped samples and tests were performed according to ASTM 1252.

\subsection{Sorption study}

Aqueous solutions containing $\mathrm{Pb}^{2+}$ ions of concentration 100, 200, 300 and $400 \mathrm{mg} / \mathrm{l}$ were prepared from Lead nitrate $\left(\mathrm{Pb}\left(\mathrm{NO}_{3}\right)_{2}\right.$, Merck No.7397). $0.01 \mathrm{~g}$ of nano TCP was introduced in a stirred tank reactor containing $500 \mathrm{ml}$ of the prepared solution. The stirring speed of the agitator was $300 \mathrm{rpm}$. The temperature of the suspension was maintained at $25 \pm 1^{\circ} \mathrm{C}$. The initial $\mathrm{pH}$ of the solution was adjusted to the value 6.5 by adding $\mathrm{NH}_{3}$ and $\mathrm{HCl}$. Using batch equilibration technique, the sorption capacity of nano-TCP for $\mathrm{Pb}^{2+}$ cation as well as the influence of the initial concentration of $\mathrm{Pb}^{2+}$ cation, adsorbent mass, contact time and temperature, sorption experiments was determined.

Samples were taken after mixing the adsorbent and $\mathrm{Pb}^{2+}$ ion bearing solution at pre determined time intervals $(5,10,20,30,60$, and $120 \mathrm{~min})$ for the measurement of residual metal ion concentration in the solution and to ensure equilibrium was reached. The samples volume taken is $2 \mathrm{ml}$. After each specified time, the sorbents were separated from the solution by centrifuge and filtration through the filter paper (Whatman grade 6). The exact concentration of metal ions was determined by AAS (GBC 932 Plus atomic absorption spectrophotometer). Two replicates were used for each $\mathrm{Pb}^{2+}$ sorption experiments and the results given were the average values.

The mass balance of lead is given by:

$$
m q=V\left(C_{0^{-}} C\right)
$$

Where $m, q, V, C_{0}$, and $C$ are the mass of nano-TCP (g), amount of lead removed by unit of weight of TCP (Uptake capacity: $\mathrm{mg} \mathrm{Pb} / \mathrm{g}$ TCP), volume of lead solution (L), initial lead concentration of solution $(\mathrm{mg} \mathrm{Pb} / \mathrm{l})$, and the concentration of lead at the time $t$ of adsorption (mg Pb/l). After $120 \mathrm{~min}, C$ and $q$ will reach equilibrium value $C_{\mathrm{e}}$ and $q_{\mathrm{e}}$. The percent removal $(\%)$ and distribution ratio $\left(\mathrm{K}_{\mathrm{d}}\right)$ were calculated using the following equations.

$$
\%_{\text {Removal }}=\frac{\left(c_{0}-C_{f}\right)}{C_{0}} \times 100
$$

Where $C_{0}$ and $C_{\mathrm{f}}$ are the concentrations of the metal ion in initial and final solutions (after $120 \mathrm{~min}$ ) respectively, and 
Bulletin de la Société Royale des sciences de Liège, Vol. 86, articles, 2017, p. 96 - 112

$$
K_{d}=\frac{\text { amount of metal in adsorbent }}{\text { amount of metal in solution }} \times \frac{V}{m}
$$

Where $V$ is the volume of the solution $(\mathrm{ml})$ and $m$ is the weight of the adsorbent $(\mathrm{g})$.

\section{Results and Discussion}

\subsection{Characteristics of adsorbent}

TEM micrograph of the nano TCP powders after drying at $80{ }^{\circ} \mathrm{C}$ is shown in Fig. 1 . The microstructure of TCP crystalline after drying was almost needle shape, with a size in the range of $20-30 \mathrm{~nm}$. The crystalline structure analysis of TCP particles was performed, using $\mathrm{X}$ ray diffraction, and the obtained diffractometers are represented in Fig. 2. The reflection patterns matched the ICDD standards (JCPDS) for TCP phase. The patterns only showed the peaks characteristic of TCP with no obvious evidences on the presence of other additional phases. The broad peaks around (-414) and (-314) planes indicated that the crystallites were very tiny in nature with much atomic oscillations. The analysis of the nano TCP sample has confirmed a low-crystalline product, with the specific surface area $70 \mathrm{~m}^{2} / \mathrm{g}$.

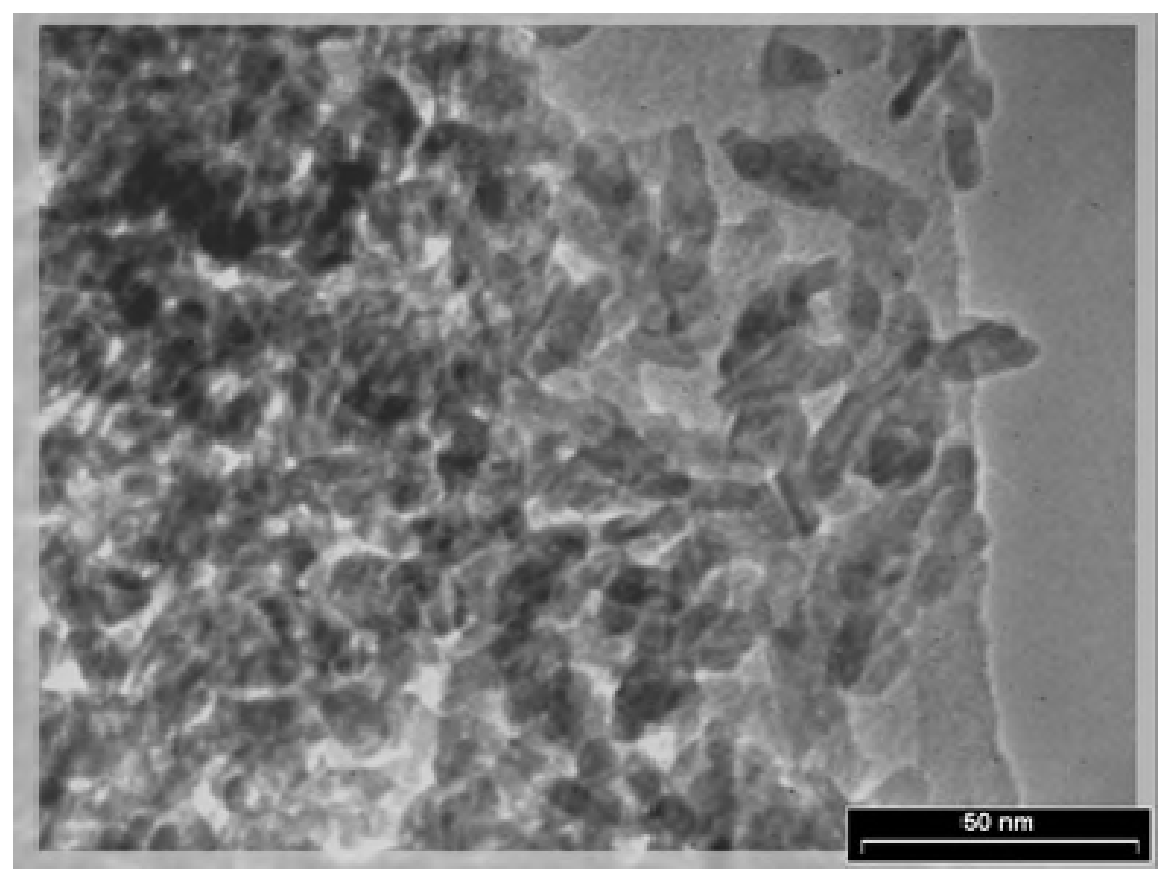

Fig. 1: TEM micrograph of nano Tricalcium phosphate after drying at $80^{\circ} \mathrm{C}$. 


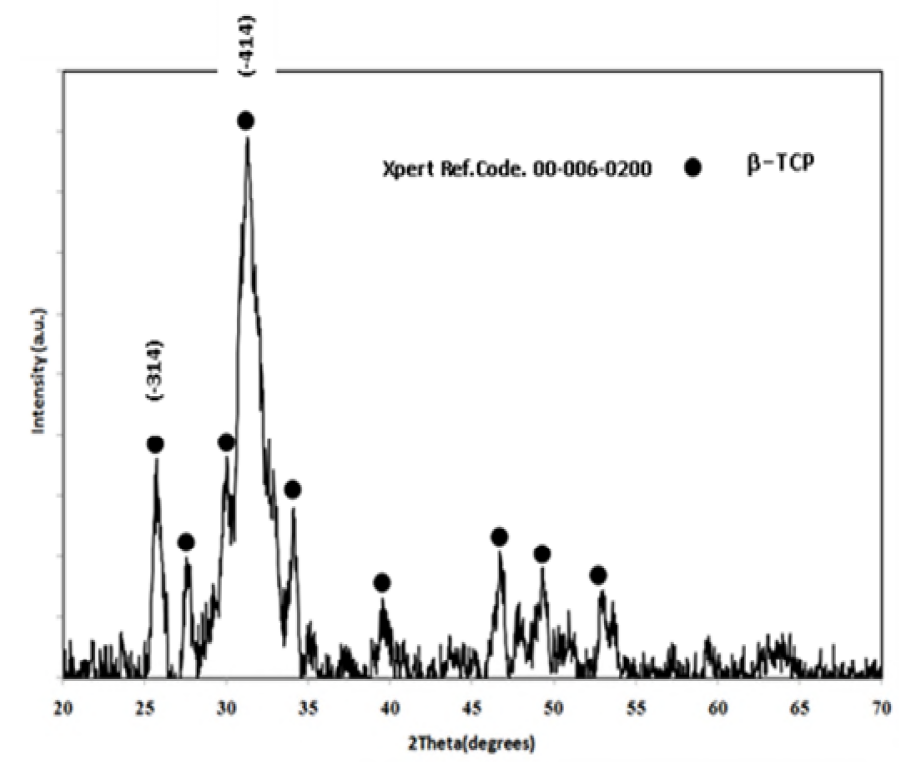

Fig. 2: XRD pattern of nano Tricalcium phosphate powders after drying at $80^{\circ} \mathrm{C}$.

\subsection{Effect of initial Pb ${ }^{2+}$ concentration and adsorbent dosage}

The sorption of $\mathrm{Pb}^{2+}$ cations was carried out at different initial lead concentrations ranging from 100 to $400 \mathrm{mg} / \mathrm{l}$, at $\mathrm{pH} 6$, at $300 \mathrm{rpm}$ with $120 \mathrm{~min}$ of contact time using nano TCP. The uptake of the $\mathrm{Pb}^{2+}$ ion is increased by increasing the initial metal concentration tending to saturation at higher metal concentrations. As shown in Fig. 3.

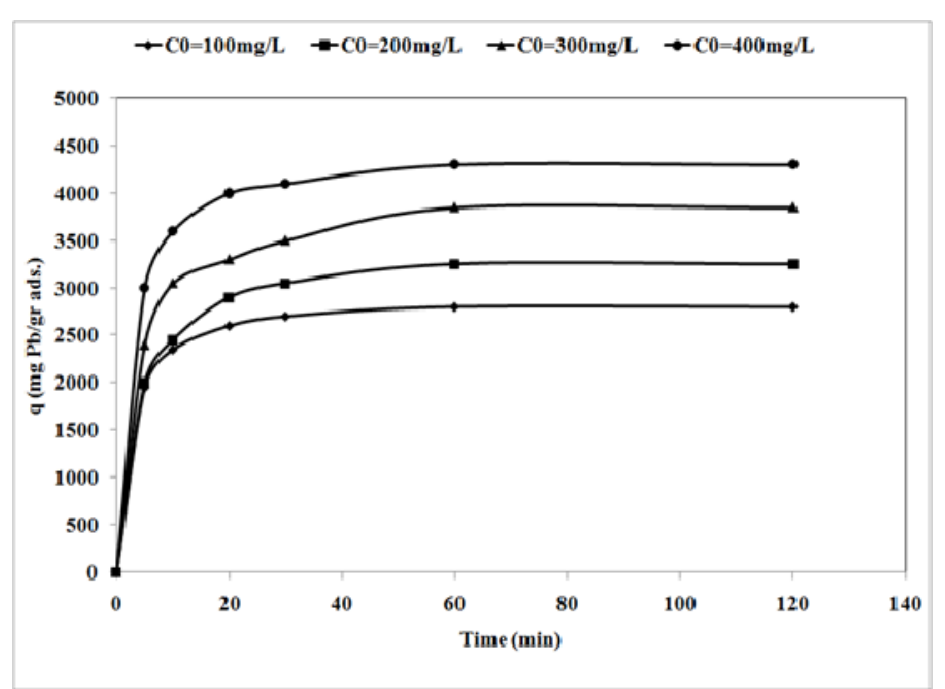

Fig. 3: Effect of initial concentration on removal of $\mathrm{Pb}^{2+}$ by nano Tricalcium phosphate sorbents ( $\mathrm{pH}$ 6, adsorbent dosage $=0.01 \mathrm{gr} / 1,300 \mathrm{rpm}$ agitating rate) .

When the initial $\mathrm{Pb}^{2+}$ cations concentration increased from 100 to $400 \mathrm{mg} / \mathrm{l}$, the uptake capacity of nano TCP increased from 2800 to $4300 \mathrm{mg} / \mathrm{g}$. A higher initial concentration provided an important driving force to overcome all mass transfer resistances of the pollutant between the aqueous and solid phases thus increased the uptake [11]. 
The effect of nano TCP dosage is depicted in Fig. 4. Evidently, percentage removal increased with the increase of the sorbent mass (Fig. 4 (a)) and the uptake capacity of $\mathrm{Pb}^{2+}$ decreased from $4300 \mathrm{mg} / \mathrm{g}(21.5 \%$ removal $)$ to $2500 \mathrm{mg} / \mathrm{g}$ (37.5\% removal) with increasing nano TCP concentration from 0.01 to $0.03 \mathrm{~g} / \mathrm{l}$ (Fig. 4 (b)). This was attributed to a higher dosage of sorbent due to the increased surface area providing more adsorption sites available which gave rise to a higher removal of $\mathrm{Pb}^{2+}$ cations [12].

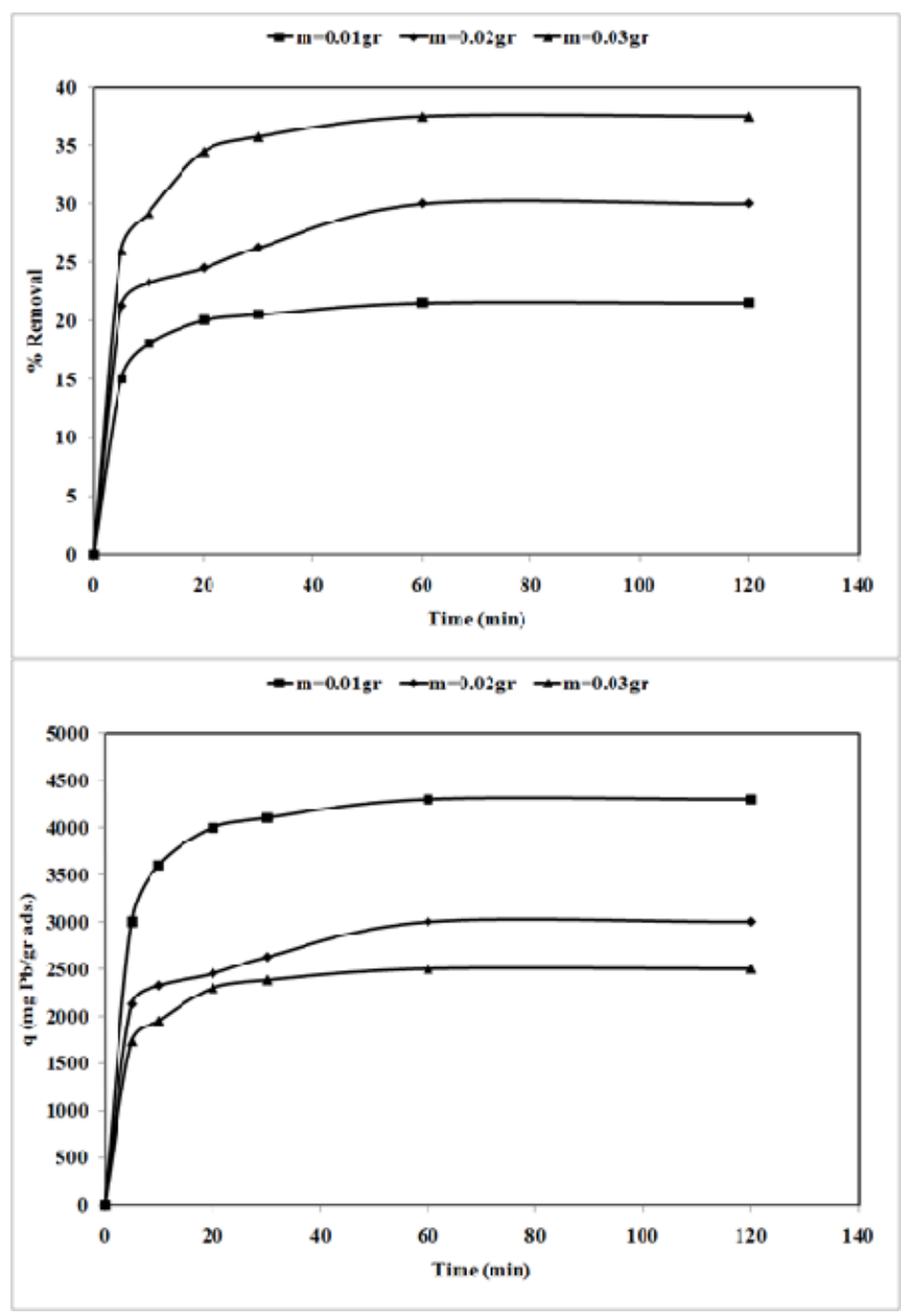

(a)

(b)

Fig. 4: Effect of adsorbent dosage on percentage removal (a) and uptake capacity (b) of $\mathrm{Pb}^{2+}$ by nano Tricalcium phosphate $(\mathrm{pH} 6$, initial metal concentration $=400 \mathrm{mg} / \mathrm{L}, 300 \mathrm{rpm}$ agitating rate).

\subsection{Effect of temperature and Determination of thermodynamic parameters}

To study the effect of temperature parameter on the uptake of $\mathrm{Pb}^{2+}$ cation by nano-TCP in aqueous solution, temperatures of 25,45 and $65^{\circ} \mathrm{C}$ were selected. Fig.5 (a) illustrates the relationship between temperature and the amount of $\mathrm{Pb}^{2+}$ cation adsorbed onto nanoTCP at equilibrium time $(120 \mathrm{~min})$. As seen, the adsorption of $\mathrm{Pb}^{2+}$ cation on nano-TCP increased from $4300 \mathrm{mg} / \mathrm{g}$ ( $21.5 \%$ removal) to $5000 \mathrm{mg} / \mathrm{g}$ ( $25 \%$ removal) when the temperature was increased from 25 to $65^{\circ} \mathrm{C}$ at an initial concentration of $400 \mathrm{mg} / \mathrm{l}$. 


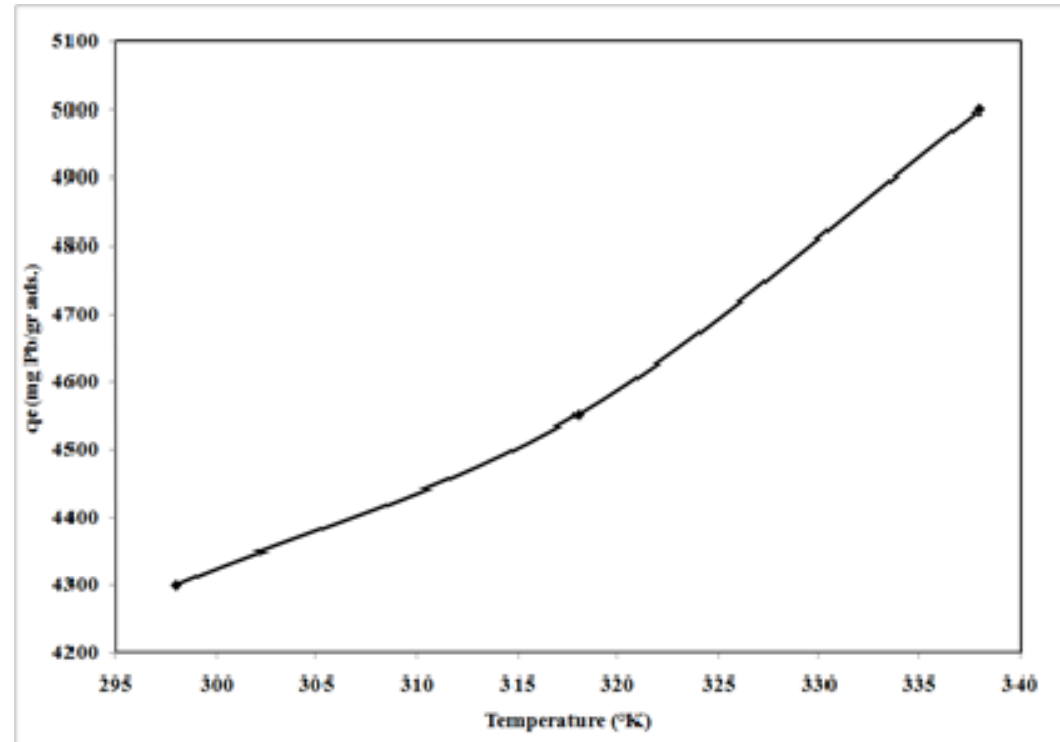

(a)

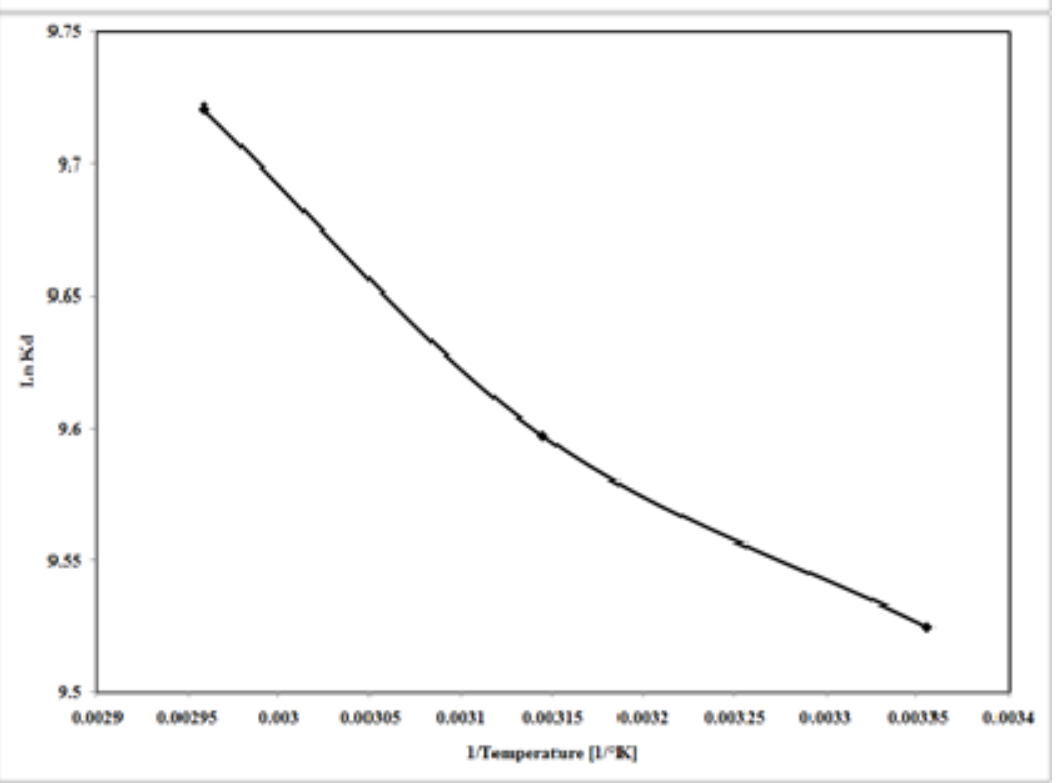

(b)

Fig.5: The uptake capacity of $\mathrm{Pb}^{2+}$ ions at different temperature (a) and plot of $\ln K_{\mathrm{d}}$ versus $1 / T$ (b) $\left(\mathrm{pH} \mathrm{6}\right.$, initial metal concentration $=400 \mathrm{mg} \mathrm{l}^{-1}$, adsorbent dosage $=0.01 \mathrm{~g} \mathrm{l}^{-1}, 300 \mathrm{rpm}$ agitating rate)

The increase in the equilibrium sorption of $\mathrm{Pb}^{2+}$ cation with temperature indicated that $\mathrm{Pb}^{2+}$ cation removal by adsorption on nano-TCP favored a high temperature condition. This could be the result of an increase in the mobility of the $\mathrm{Pb}^{2+}$ cation with temperature. An increasing number of molecules could also acquire sufficient energy to undergo an interaction with active sites at the surface. Furthermore, increasing temperature may produce a swelling effect within the internal structure of the nano-TCP enabling large metal ions to penetrate further [13].

Thermodynamic parameters such as free energy $(\Delta G)$, enthalpy $(\Delta H)$, and entropy $(\Delta S)$ changes can be estimated using equilibrium constants changing as a function of temperature. The free energy changes of the sorption reaction are given by the following equation: 


$$
\Delta G=-\mathrm{RT} \ln K_{\mathrm{d}}
$$

where $(\Delta G)$ is free energy changes $(\mathrm{J}) ; R$ is the universal gas constant, $8.314 \mathrm{~J} / \mathrm{mol} . \mathrm{K}$ and $T$ is the absolute temperature $(\mathrm{K})$.

$$
\Delta G=\Delta H-\mathrm{T} \Delta S
$$

The distribution ratio $\left(K_{\mathrm{d}}\right)$ values increased with raising temperature (Fig5 (b)), indicating the endothermic nature of adsorption. A plot of Gibbs free energy changes, $(\Delta G)$, versus temperature, $T(\mathrm{~K})$; was found to be linear. The values of $\Delta H$ and $\Delta S$ were determined from the slope and intercept of the plots. The thermodynamic parameters Gibbs free energy change, $\Delta G$, are shown in Table 1 . The enthalpy, $\Delta G$, and the entropy changes, $\Delta S$, for the sorption processes were calculated to be $4140 \mathrm{~J} / \mathrm{mol}$ and $92.98 \mathrm{~J} / \mathrm{mol} . \mathrm{K}$, respectively.

Table.1: Thermodynamic parameters for the adsorption of $\mathrm{Pb}^{2+}$ onto nano- $\mathrm{TCP}$ in aqueous solutions

\begin{tabular}{ccccc}
\hline $\boldsymbol{T} / \mathbf{K}$ & $\boldsymbol{K}_{\mathbf{d}}$ & $\Delta \boldsymbol{G}^{\circ}(\mathbf{J} / \mathbf{m o l})$ & $\Delta \boldsymbol{H}^{\circ}(\mathbf{J} / \mathbf{m o l})$ & $\Delta \boldsymbol{S}^{\circ}(\mathbf{J} / \mathbf{m o l} . \mathbf{K})$ \\
\hline \hline 298 & & & & \\
318 & 13694.27 & -23598.2 & 4140 & 92.98 \\
338 & 14724.92 & -25373.8 & & \\
& 16666.67 & -27317.8 & & \\
\hline
\end{tabular}

The negative values of $\Delta G$ at various temperatures indicated the spontaneous nature of the adsorption process. The positive value of $\Delta S$ indicated that there is an increment in the randomness in the system solid/solution interface during the adsorption process. In addition, the positive value of $\Delta H$ indicated that the adsorption was endothermic. The positive value of $\Delta S$ reflected the affinity of the nano-TCP for $\mathrm{Pb}^{2+}$ cation and suggested some structural changes in lead and nano-TCP [14].

\subsection{Effect of contact time and sorption kinetic}

Effect of contact time was studied using solution containing $400 \mathrm{mgl}^{-1}$ concentration of $\mathrm{Pb}^{2+}$ ion using nano-TCP at $\mathrm{pH}=6$ up to a contact time of $120 \mathrm{~min}$. It seemed that the adsorption consisted of two phases: a primary rapid phase and a second slow phase. The first rapid phase lasted approximately $10 \mathrm{~min}$ and accounted for the major part in the total $\mathrm{Pb}^{2+}$ adsorption. Adsorption reached a plateau value in approximately $60 \mathrm{~min}$, which showed saturation of the active points (Fig. 3).

The sorption kinetics may be controlled by various diffusion mechanisms: (a) bulk diffusion, (b) film diffusion, and (c) intraparticle diffusion. Three models were used for the description of kinetic profiles based on the pseudo-first order equation (the so-called Lagergren equation), on the pseudo-second-order equation described by Ho (2006), and on the intraparticle diffusion model.

The pseudo-first order equation of Lagergren can be expressed as Eq. (6):

$$
\log \left(q_{\mathrm{e}}-q\right)=\log q_{\mathrm{ecal}}-\left(\mathrm{k}_{1} / 2.303\right) t
$$


where $q$ is the amount of metal ions adsorbed (mg. $\left.\mathrm{g}^{-1}\right)$ at any given time $t(\mathrm{~min}), q_{\mathrm{e}}$ is the amount of metal ion adsorbed (mg. ${ }^{-1}$ ) at equilibrium and $k_{1}$ is the pseudo-first order reaction rate constant for adsorption $\left(\mathrm{min}^{-1}\right)$. The pseudo-second order reaction rate equation has the form:

$$
\frac{t}{q_{t}}=\frac{1}{k_{2} q_{\text {e cal }}^{2}}+\frac{t}{q_{\text {e cal }}}
$$

where $q_{\mathrm{t}}$ is the amount of metal ions adsorbed (mg.g $\mathrm{g}^{-1}$ ) at any given time $t(\mathrm{~min}), q_{\mathrm{e}}$ is the amount of metal ion adsorbed (mg. $\left.\mathrm{g}^{-1}\right)$ at equilibrium and $k_{2}$ is the second order reaction rate constant for adsorption $\left(g(\mathrm{mg} \cdot \mathrm{min})^{-1}\right)$.

The intraparticle diffusion model [15] was considered in order to determine the participation of this process in the sorption of lead ion by nano-TCP. According to this model, the plot of uptake $\left(q_{\mathrm{t}}\right)$, versus the square root of time $\left(t^{0.5}\right)$ should be linear if intraparticle diffusion is involved in the overall adsorption mechanism. Furthermore, if this line passes through the origin then the intraparticle diffusion is the rate-controlling step of the process [16]. The initial rate of intraparticle diffusion, $K_{\mathrm{D}}$, can be calculated in the following way:

$$
q_{t=K_{D}} \cdot t^{0.5}
$$

where $q_{\mathrm{t}}$ is the amount of sorbate on the surface of the sorbent at time $t\left(\mathrm{mg}^{\mathrm{g}} \mathrm{g}^{-1}\right), K_{\mathrm{D}}$ is the intraparticle rate constant $\left(m g\left(\mathrm{~g} \cdot \mathrm{min}^{0.5}\right)^{-1}\right)$ and $t$ is the time (min).

Fig. 6A and B show linear plots of the pseudo-first order model in Eq. (6) and the pseudo-second order model in Eq. (7) for the adsorption of $\mathrm{Pb}^{2+}$ onto nano-TCP. $K_{1}, K_{2}$ and $q_{\mathrm{e}}$ calculated from the slopes and intercepts of the lines obtained by plotting $\log \left(q_{\mathrm{e}}-q_{\mathrm{t}}\right)$ against $\mathrm{t}$ and $t / q_{\mathrm{t}}$ against $\mathrm{t}$ are listed in Table 2 . As shown in Table 2, the pseudo-second order model fits better the adsorption kinetics of lead ion on nano-TCP than the pseudo-first order model. This suggests that the rate limiting step of this sorption system may be chemical sorption or chemisorptions involving valency forces through sharing or exchange of electrons between sorbent and sorbate $[17,18]$. The $q_{\mathrm{e}}$ calculated from the pseudo-second order rate model of $\mathrm{Pb}^{2+}$ is $5000 \mathrm{mgg}^{-1}$. Fig. 6C shows a plot of the Weber and Morris intraparticle diffusion model for the sorption of $\mathrm{Pb}^{2+}$ onto nano-TCP. As shown in Fig. 6C, the plot of uptake $\left(q_{\mathrm{t}}\right)$, versus the square root of time $\left(t^{0.5}\right)$ was not linear, which indicated that the intraparticle diffusion was not the rate-controlling step in these adsorption systems. 
Bulletin de la Société Royale des sciences de Liège, Vol. 86, articles, 2017, p. 96 - 112
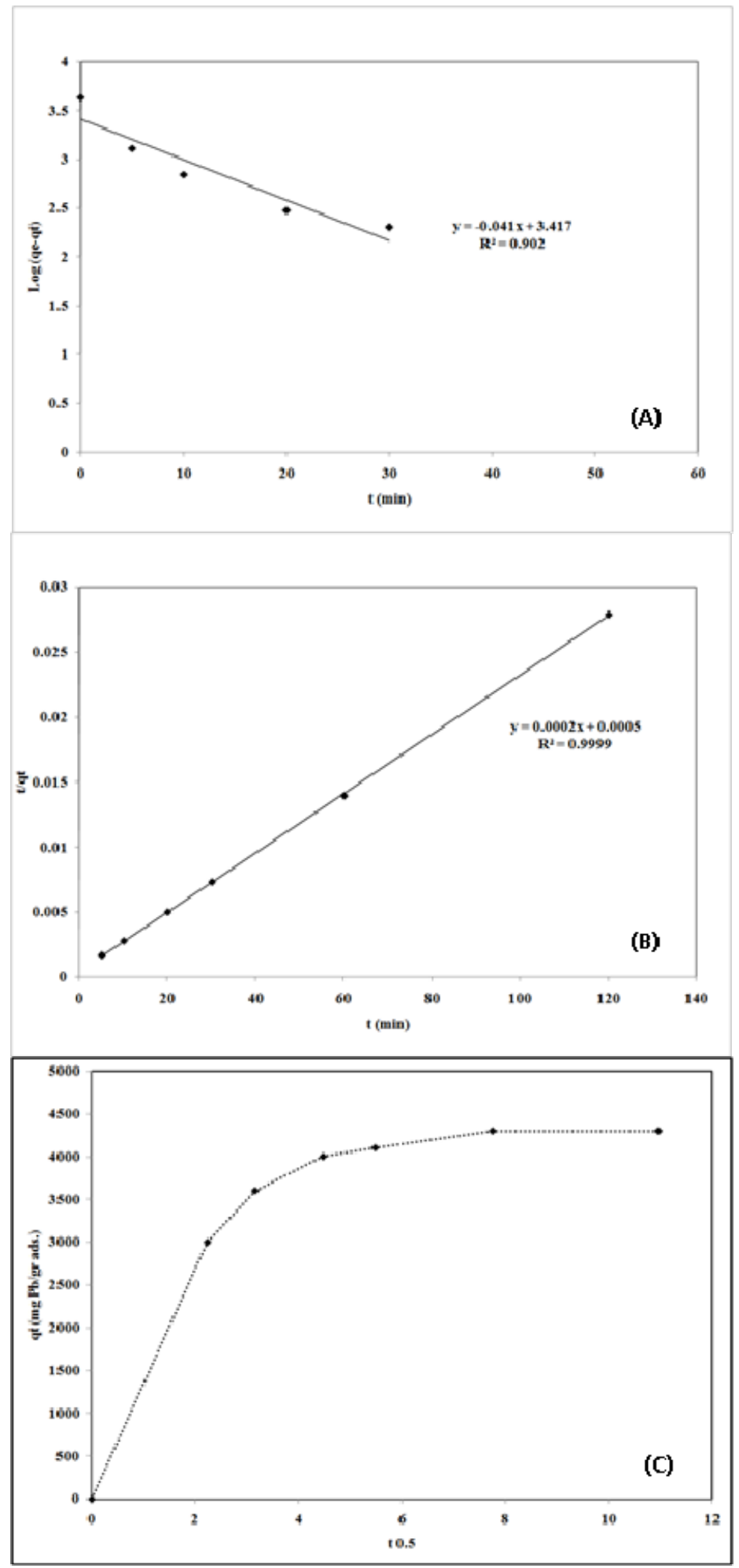

Fig.6: Linear fit of experimental data obtained using:

(A) pseudo-first-order model

(B) pseudo-second order model

(C) the amount of single metal ion sorbed versus square root of time 
Bulletin de la Société Royale des sciences de Liège, Vol. 86, articles, 2017, p. 96 - 112

Table 2: Parameter values calculated using the pseudo-first order and the pseudo-second order models for the adsorption of $\mathrm{Pb}^{2+}$ on nano TCP in aqueous solutions.

\begin{tabular}{|c|c|c|c|}
\hline \multicolumn{5}{|c|}{ pseudo-first-order kinetic model } \\
\hline & $\mathrm{K}_{1}\left[\mathrm{~min}^{-1}\right]$ & $q_{\mathrm{e} \mathrm{cal}}[\mathrm{mg} / \mathrm{g}]$ & $\mathrm{R}^{2}$ \\
\hline $\mathrm{T}\left[{ }^{\circ} \mathrm{C}\right]$ & 0.09442 & 2612.16 & 0.902 \\
\hline 25 & pseudo-second-order kinetic model \\
\hline $\mathrm{T}\left[{ }^{\circ} \mathrm{C}\right]$ & $\mathrm{K}_{2}\left[\mathrm{~min}^{-1}\right]$ & $q_{\mathrm{e} \mathrm{cal}}[\mathrm{mg} / \mathrm{g}]$ & $\mathrm{R}^{2}$ \\
\hline 25 & 0.00008 & 5000 & 0.999 \\
\hline
\end{tabular}

\subsection{Adsorption isotherms}

Analysis of the equilibrium data is important to develop an equation which accurately represents the results and can be used for the design purposes [19]. Several isotherm equations have been used for the equilibrium modeling of adsorption systems.

The sorption data have been subjected to different sorption isotherms, namely, Langmuir, Freundlich, and Dubinin-Kaganer-Radushkevich (DKR).

Table 3: Langmuir, Freundlish and Dubinin-Kaganer-Radushkevich (DKR) constants for sorption of $\mathrm{Pb}^{2+}$ onto nano-TCP in aqueous solution

\begin{tabular}{ccc}
\hline Langmuir adsorption isotherms constants & & \\
\hline $\mathrm{Q}_{0}(\mathrm{mg} / \mathrm{g})$ & $\mathrm{K}(\mathrm{L} / \mathrm{mg})$ & $\mathrm{R}^{2}$ \\
4761.90 & 0.02 & 0.982 \\
\hline Freundlich adsorption isotherms constants & & \\
\hline $\mathrm{k}_{\mathrm{f}}(\mathrm{mg} / \mathrm{g})$ & $\mathrm{n}$ & $\mathrm{R}^{2}$ \\
1214.39 & 4.69 & 0.943 \\
\hline DKR adsorption isotherms constants & & \\
\hline $\mathrm{X}_{\mathrm{m}}(\mathrm{mg} / \mathrm{g})$ & $\beta\left(\mathrm{mol}^{2} / \mathrm{J}^{2}\right)$ & $\mathrm{R}^{2}$ \\
7446.31 & $-2 \times 10^{-9}$ & 0.926 \\
\hline
\end{tabular}

The equilibrium data for metal ions over the concentration range from 100 to $400 \mathrm{mg} / \mathrm{l}$ at $25^{\circ} \mathrm{C}$ were correlated with the Langmuir isotherm [20]:

$$
\frac{C_{e}}{q_{e}}=\frac{1}{Q_{0} K}+\frac{C_{e}}{Q_{0}}
$$

Where $C_{\mathrm{e}}$ is the equilibrium concentration of metal in solution $(\mathrm{mg} / \mathrm{l}), \mathrm{q}_{\mathrm{e}}$ is the amount absorbed at equilibrium onto nano-TCP $(\mathrm{mg} / \mathrm{g}), Q_{0}(\mathrm{mg} / \mathrm{g})$ and $K(1 / \mathrm{mg})$ are Langmuir constants related to sorption capacity and sorption energy, respectively. Maximum sorption capacity $\left(Q_{0}\right)$ represents monolayer coverage of sorbent with sorbate and $K$ represents enthalpy of sorption and should vary with temperature. A linear plot was obtained when $C_{\mathrm{e}} / q_{\mathrm{e}}$ was plotted against $C_{\mathrm{e}}$ over the entire concentration range of metal ions investigated. 
Bulletin de la Société Royale des sciences de Liège, Vol. 86, articles, 2017, p. 96 - 112
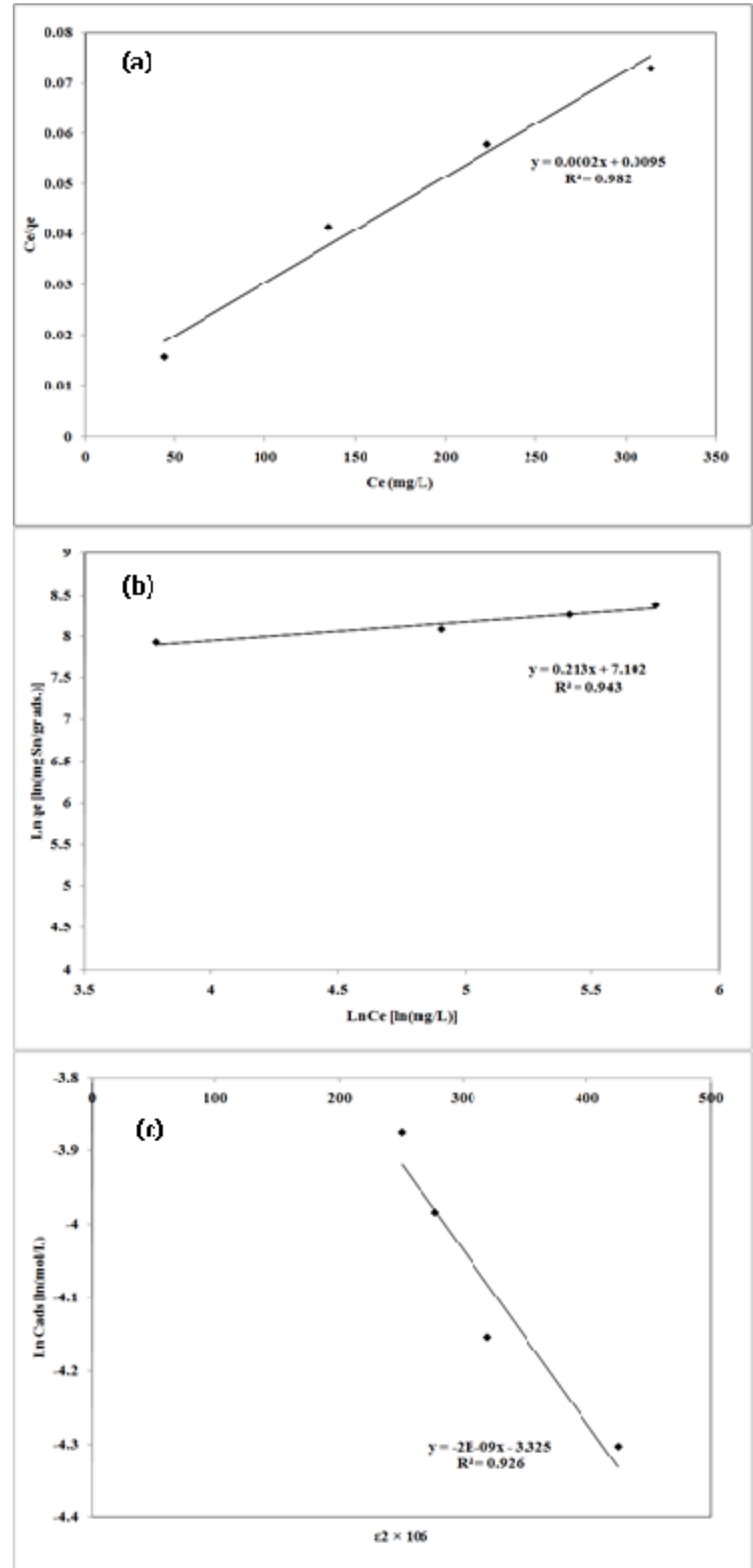

Fig. 7: Linear fits of experimental data obtained using Langmuir (a), Freundlich (b) and DubininKaganer-Radushkevich (c) sorption isotherms for the adsorption of $\mathrm{Pb}^{2+}$ onto nano-TCP in aqueous solution 
The Plotted Langmuir adsorption isotherms of $\mathrm{Pb}^{2+}$ cation are given in Fig.7 (a). An adsorption isotherm is characterized by certain constants which values express the surface properties and affinity of the sorbent and can also be used to find the sorption capacity of sorbent.

The Freundlich sorption isotherm, one of the most widely used mathematical descriptions, usually fits the experimental data over a wide range of concentrations. This isotherm gave an expression encompassing the surface heterogeneity and the exponential distribution of active sites and their energies. The Freundlich adsorption isotherms were also applied to the removal of $\mathrm{Pb}^{2+}$ cation on nano-TCP in aqueous solution (Fig.7 (b)).

$$
L n q_{e}=\operatorname{Lnk}_{f}+\frac{1}{n} \operatorname{Lnc} c_{e}
$$

Where $q_{\mathrm{e}}$ is the amount of metal ion adsorbed at equilibrium per gram of adsorbent $(\mathrm{mg} / \mathrm{g}), C_{\mathrm{e}}$ is the equilibrium concentration of metal ion in the solution $(\mathrm{mg} / \mathrm{l}), k_{\mathrm{f}}$ and $n$ are the Freundlich model constants [21, 22]. Freundlich parameters, $k_{\mathrm{f}}$ and $n$, were determined by plotting $\ln q_{\mathrm{e}}$ versus $\ln C_{\mathrm{e}}$. The numerical value of $1 / n<1$ indicates that adsorption capacity is only slightly suppressed at lower equilibrium concentrations. This isotherm does not predict any saturation of the sorbent by the sorbate; thus infinite surface coverage is predicted mathematically, indicating multilayer adsorption on the surface [23].

The Dubinin-Kaganer-Radushkevich (DKR) has been used to describe the sorption of metal ions on clays. The DKR equation has the form:

$$
\operatorname{Ln} C_{a d s}=\operatorname{Ln} X_{m}-\beta \varepsilon^{2}
$$

Where $C_{\text {ads }}$ is the number of metal ions adsorbed per unit weight of adsorbent $(\mathrm{mol} / \mathrm{g})$, $X_{\mathrm{m}}(\mathrm{mol} / \mathrm{g})$ is the maximum sorption capacity, $\beta\left(\mathrm{mol}^{2} / \mathrm{J}^{2}\right)$ is the activity coefficient related to mean sorption energy, and $\varepsilon$ is the Polanyi potential, which is equal to:

$$
\varepsilon=R T \ln (1+1 / C e)
$$

Where $R$ is the gas constant $(8.314 \mathrm{~kJ} / \mathrm{mol} . \mathrm{K})$ and $T$ is the temperature $(K)$. The saturation limit $X_{\mathrm{m}}$ may represent the total specific micro pore volume of the sorbent. The sorption potential is independent of the temperature but varies according to the nature of sorbent and sorbate [24]. The slope of the plot of $\ln C_{\text {ads }}$ versus $\varepsilon^{2}$ gives $\beta\left(\mathrm{mol}^{2} / \mathrm{J}^{2}\right)$ and the intercept yields the sorption capacity, $X_{\mathrm{m}}(\mathrm{mol} / \mathrm{g})$. The sorption space in the vicinity of a solid surface is characterized by a series of equipotential surfaces having the same sorption potential. The sorption energy can also be worked out using the following relationship:

$$
E=1 / \sqrt{-2 \beta}
$$

It is known that magnitude of apparent adsorption energy $\mathrm{E}$ is useful for estimating the type of adsorption and if this value is below $8 \mathrm{~kJ} / \mathrm{mol}$ the adsorption type can be explained by physical adsorption, between 8 and $16 \mathrm{~kJ} / \mathrm{mol}$ the adsorption type can be 
explained by ion exchange, and over $16 \mathrm{~kJ} / \mathrm{mol}$ the adsorption type can be explained by a stronger chemical adsorption than ion exchange [25-27].

The plot of $\operatorname{Ln} C_{\text {ads }}$ against $\varepsilon^{2}$ for metal ion sorption on nano-TCP is shown in Fig.7 (c). The Langmuir, Freundlich and DKR adsorption constants from the isotherms and their correlation coefficients are also presented in Table 3.

The correlation coefficients $R^{2}(0.982,0.943$ and 0.926 for Langmuir, Freundlich and DKR model, respectively) confirmed good agreement between both theoretical models and experimental results in the present study. The maximum sorption capacity, $Q_{0}$, calculated from Langmuir equation was $4761.90 \mathrm{mg} / \mathrm{g}$, while Langmuir constant $\mathrm{K}$ was $0.02 \mathrm{~L} / \mathrm{mg}$. The values obtained for $\mathrm{Pb}^{2+}$ cation from the Freundlich model showed a maximum adsorption capacity $\left(K_{\mathrm{f}}\right)$ of $1214.39 \mathrm{mg} / \mathrm{g}$ with an affinity value $(n)$ equal to 4.69. The values of sorption constants, derived from DKR model were $7446.31 \mathrm{mg} / \mathrm{g}$ (35.97 $\mathrm{mmol} / \mathrm{g}$ ) for $X_{\mathrm{m}},-2 \times 10^{-9} \mathrm{~mol}^{2} / \mathrm{J}^{2}$ for $\beta$ and $15.81 \mathrm{~kJ} / \mathrm{mol}$ for $E$.

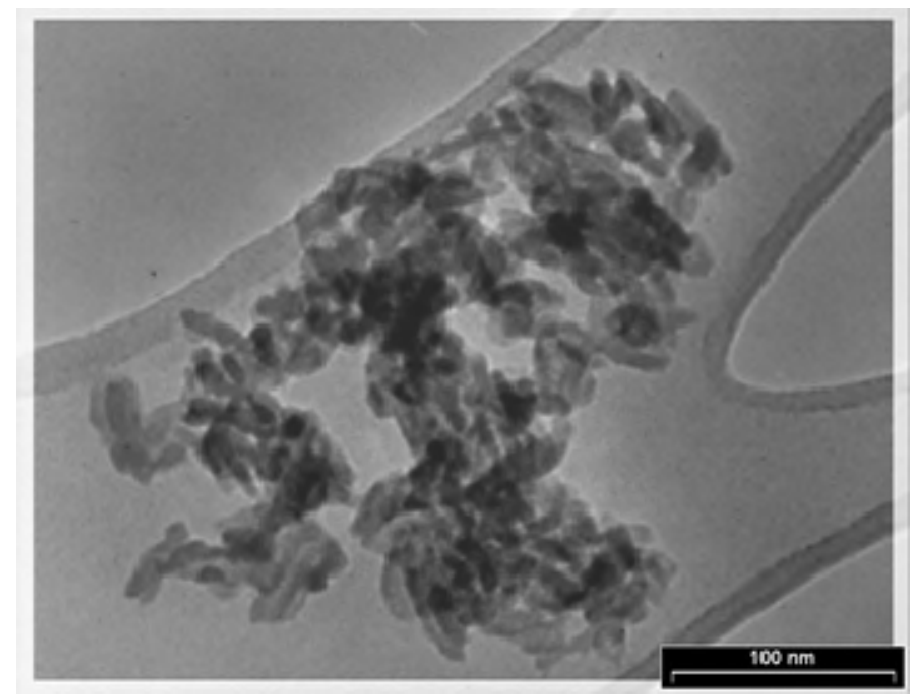

(a)

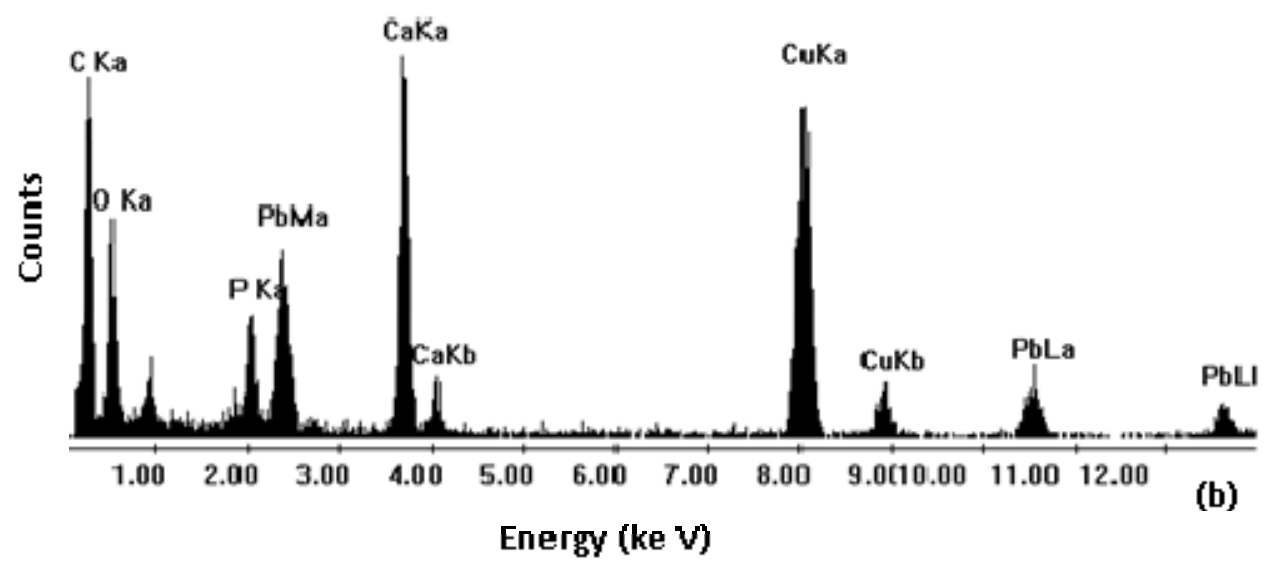

Fig. 8: TEM micrograph (a) and EDS spectrum (b) of the solid residue with maximum amount of uptake capacity of $\mathrm{Pb}^{2+}$, respectively.

The values indicated that the adsorption pattern for $\mathrm{Pb}^{2+}$ cation on nano-TCP followed third, the DKR isotherm $\left(R^{2}>0.926\right)$, the Freundlich isotherm $\left(R^{2}>0.943\right)$ and the Langmuir isotherm $\left(R^{2}>0.982\right)$ at all experimental. It is clear that the Langmuir 
isotherm has best fitted for the sorption of $\mathrm{Pb}^{2+}$ cations on nano-TCP in aqueous solution. When the system is in a state of equilibrium, the distribution of $\mathrm{Pb}^{2+}$ cation between the nano-TCP and the $\mathrm{Pb}^{2+}$ solution is of fundamental importance in determining the maximum sorption capacity of nano-TCP for the lead ion from the isotherm. The $E$ values are $15.81 \mathrm{~kJ}$ for $\mathrm{Pb}^{2+}$ cation on the nano-TCP. It is the orders of an ion-exchange mechanism, in which the sorption energy lies within $8-16 \mathrm{~kJ} / \mathrm{mol}$.

The TEM of $\mathrm{Pb}^{2+}$-loaded sample particles is shown in Fig. 8 (a) indicating that most crystalline are rounded with dimensions in the range of 20-30 nm. No morphology of nano-TCP loaded $\mathrm{Pb}^{2+}$ was detected by the TEM crystalline analysis of the solid residue with maximum amount of uptake capacity of $\mathrm{Pb}^{2+}$.

Fig. 8 (b) shows the EDS spectrum and powder diffraction pattern of the $\mathrm{Pb}^{2+}$-loaded sample particles. Clear peaks corresponding to $\mathrm{Ca}, \mathrm{P}, \mathrm{O}$ and $\mathrm{Pb}$ were observed in the EDS spectrum. The EDS spectrum confirms its chemical composition and powder diffraction pattern further validate the crystallinity of the synthesized powder. In addition, $\mathrm{Cu}$ peaks were also observed in the EDS spectrum. The peaks for $\mathrm{Cu}$ arise from stray scattering of X-rays from the copper grid.

\section{Conclusions}

The present investigation showed that the nano TCP was an effective adsorbent for the removal of $\mathrm{Pb}^{2+}$ cations from aqueous solutions. The adsorption process was a function of the adsorbent dosage, initial $\mathrm{Pb}^{2+}$ cations concentration and temperature. The efficiency of $\mathrm{Pb}^{2+}$ cations adsorption increased with an increase in the adsorbent dosage. Thermodynamic calculations showed that the lead sorption process of nano-TCP had endothermic and spontaneous nature. The pseudo-first order, pseudo-second order kinetic and intraparticle diffusion kinetic models were used to describe the kinetic data for initial $\mathrm{Pb}^{2+}$ concentrations and the rate constants were evaluated. The used experimental data were fitted by the second-order kinetic model, which indicated that chemical sorption was the rate-limiting step, inside of mass transfer. The contact time of approximately $60 \mathrm{~min}$ was required to reach the equilibrium. Isotherm studies indicated that the Langmuir model fitted the experimental data better than Freundlich and DKR models. The adsorption equilibrium was described well by the Langmuir isotherm model with maximum adsorption capacity of $4761.90 \mathrm{mg} / \mathrm{g}$ of $\mathrm{Pb}^{2+}$ on nano-TCP in aqueous solution.

\section{Acknowledgment}

This research was completely supported by Maybod Branch, Islamic Azad University and will be grateful.

\section{References}

[1] U. Ulusoy, and R. Akkaya, "Adsorptive features of polyacrylamide-apatite composite for $\mathrm{Pb}^{2+}, \mathrm{UO}_{2}{ }^{2+}$ and $\mathrm{Th}^{4+}$, Journal of Hazardous Materials, 163 (2009) 98108.

[2] I. Mobasherpour, E. Salahi and M. Pazouki, "Potential of nano crystalline hydroxyapatite for lead (II) removal from aqueous solutions: Thermodynamic and 
Adsorption isotherm study" African Journal of Pure and Applied Chemistry, 5(11) (2011) 383-392.

[3] J. Vangronsveld, J. Colpaert, K.V. Tichelen, "Reclamation of a bare industrial area polluted by nonferrous metals: Physico-chemical and biological evaluation of the durability of soil treatment and revegetation" Environmental Pollution, 94, (1996) 131140.

[4] S.J.T. Pollard, G.D. Fowlerr, C.J. Sollars, R. Perry, "Low-cost adsorbents for waste and waste water treatment: a review" Science of the Total Environment, 116 (1992) 3152.

[5] A. Krestou, A. Xenidis, D. Panias, "Mechanism of aqueous uranium (VI) uptake by hydroxyapatite" Minerals Engineering, 17 (2004) 373-381.

[6] I. Mobasherpour, E. Salahi, S.A. Manafi, R. Darvishi Kamachali, "Effect of heattreatment on grain growth of nanocrystalline tricalcium phosphate powder synthesized via the precipitation method" Materials Science-Poland, 29 (3) (2011) 203-208.

[7] Z. Zhang, M. Li, W. Chen, S. Zhu, N. Liu, L. Zhu, "Immobilization of lead and cadmium from aqueous solution and contaminated sediment using nanohydroxyapatite" Environmental Pollution, 158 (2010) 514-519.

[8] S.M. Mousa, N.S. Ammar, H.A. Ibrahim, "Removal of lead ions using hydroxyapatite nano-material prepared from phosphogypsum waste" Journal of Saudi Chemical Society, 20 (2016) 357-365.

[9] R. Khani, S. Sobhani, M. Hossein Beyki, "Highly selective and efficient removal of lead with magnetic nano-adsorbent: Multivariate optimization, isotherm and thermodynamic studies" Journal of Colloid and Interface Science, 466 (2016) 198-205.

[10] M. E. Mahmoud, G. M. Nabil, S. M. E. Mahmoud, "High performance nanozirconium silicate adsorbent for efficient removal of copper (II), cadmium (II) and lead (II)" Journal of Environmental Chemical Engineering, 3 (2015) 1320-1328.

[11] Z. Aksu, S. Tezer, "Biosorption of reactive dyes on the green alga Chlorella vulgaris" Process Biochemistry, 40 (2005) 1347-1361.

[12] I. Mobasherpour, E. Salahi and M. Pazouki, "Removal of divalent cadmium cations by means of synthetic nano crystallite hydroxyapatite" Desalination, 266 (2011) 142148.

[13] M. Doğan, and M. Alkan, "Adsorption kinetics of methyl violet onto perlite" Chemosphere, 50 (2003) 517-528.

[14] Y.-S. Ho, "Removal of copper ions from aqueous solution by tree fern" Water Research, 37 (2003) 2323-2330.

[15] W.J. Weber Jr and J.C. Morris, "Kinetics of Adsorption on Carbon from Solution" AMERICAN SOCIETY OF CIVIL ENGINEERS, 89 (1963) 31-60.

[16] I. Smičiklas, S. Dimović, I. Plećaš and M. Mitrić, "Removal of $\mathrm{Co}^{2+}$ from aqueous solutions by hydroxyapatite" Water Research, 40 (2006) 2267-2274.

[17] S. Lu and S.W. Gibb, "Copper removal from wastewater using spent-grain as biosorbent” Bioresource Technology, 99, (2008) 1509-1517.

[18] Y.S. Ho and G. McKay, "Pseudo-second order model for sorption processes" Process Biochemistry, 34 (1999) 451-465.

[19] Z. Aksu, "Determination of the equilibrium, kinetic and thermodynamic parameters of the batch biosorption of nickel (II) ions onto Chlorella vulgaris" Process Biochemistry, 38, (2002) 89-99.

[20] I. Langmuir, "The adsorption of gases on plane surfaces of glass, mica and platinum" Journal of the American Chemical Society, 40 (1918) 1361-1403. 
[21] E. Malkoç and Y. Nuhoglu, "The removal of chromium (VI) from synthetic wastewater by Ulothrix zonata" Fresenius Environmental Bulletin, 12 (2003) 376-381.

[22] K. Kadirvelu, K. Thamaraiselvi and C. Namasivayam, "Adsorption of nickel (II) from aqueous solution onto activated carbon prepared from coirpith" Separation and Purification Technology, 24 (2001) 497-505.

[23] S. Hasany, M. Saeed and M. Ahmed, "Sorption and thermodynamic behavior of zinc(II)-thiocyanate complexes onto polyurethane foam from acidic solutions" Journal of Radioanalytical and Nuclear Chemistry, 252 (2002) 477-484.

[24] S. Khan and M. Williams, Post-Tensioned Concrete Floors, ButterworthHeinemann, Oxford, (1995), p. 271.

[25] S.-H. Lin and R.-S. Juang, "Heavy metal removal from water by sorption using surfactant-modified montmorillonite" Journal of Hazardous Materials, 92 (2002) 315326.

[26] C.-C. Wang, L.-C. Juang, C.-K. Lee, T.-C. Hsu, J.-F. Lee and H.-P. Chao, "Effects of exchanged surfactant cations on the pore structure and adsorption characteristics of montmorillonite" Journal of Colloid and Interface Science, 280, (2004) 27-35.

[27] B.S. Krishna, D.S.R. Murty and B.S. Jai Prakash, "Thermodynamics of chromium (VI) anionic species sorption onto surfactant-modified montmorillonite clay" Journal of Colloid and Interface Science, 229 (2000) 230-236. 